\title{
Impact of orthodontic treatment need and deviant occlusal traits on oral health-related quality of life in children: A cross-sectional study in the Generation $\mathrm{R}$ cohort
}

\author{
Amanda-mae A. M. Nguee, ${ }^{a, b}$ Edwin M. Ongkosuwito, ${ }^{a, b}$ Vincent W. V. Jaddoe, ${ }^{\text {a,c,d }}$ Eppo B. Wolvius, ${ }^{\text {a,b }}$ \\ and Lea Kragt ${ }^{\mathrm{a}, \mathrm{b}}$ \\ Rotterdam, The Netherlands
}

\begin{abstract}
Introduction: Many studies have investigated the impact of orthodontic treatment need (OTN) on children's oral health-related quality of life (OHRQOL). However, few studies have explored the impact of deviant occlusal traits on OHRQOL regarding the severity of OTN. This cross-sectional study aims to address this gap in the literature. Methods: This study was conducted within the Generation R Study, a population-based prospective cohort study. We assessed OTN with the Index of Orthodontic Treatment Need and OHRQOL with a parental short-form of the Child Oral Health Impact Profile in 3048 children at a median age of 9.74 years (9.5-10.0). We also further assessed individual malocclusion traits in a subsample of 2714 children. We investigated the association between OTN, malocclusion traits, and OHRQOL using multiple regression analysis with weighted least squares. Results: Children with definite (adjusted effect estimate $=-0.81 ; 95 \%$ confidence interval -1.12 to -0.50 ) or borderline (adjusted effect estimate $=-0.34$; $95 \%$ confidence interval -0.61 to -0.08 ) OTN experienced significant decreases in their OHRQOL than those with no need. An impacted tooth, increased overjet, or crowding had significant negative impacts on children's OHRQOL. Children with an overjet experienced negative impacts on OHRQOL even when orthodontic treatment was not necessary. Conclusions: Progressively greater OTN has increasingly negative impacts on parent's perception of children's OHRQOL. In particular, children presenting with large overjets and impacted teeth have lower OHRQOL. These perspectives add to better patient-clinician communication and understanding of patient expectations around OTN, which may potentially lead to improvements in quality of care from the patient perspective. (Am J Orthod Dentofacial Orthop 2020;157:764-72)
\end{abstract}

$\mathrm{M}$ alocclusion is a common oral condition in the Netherlands, with $60 \%$ of Dutch adolescents reported having undergone orthodontic treatment. ${ }^{1}$ Individuals with malocclusion have been associated with an elevated risk of dental disease,

\footnotetext{
aThe Generation R Study Group, Erasmus University Medical Centre, Rotterdam, The Netherlands.

${ }^{\mathrm{b}}$ Department of Oral and Maxillofacial Surgery, Special Dental Care and Orthodontics, Erasmus University Medical Centre, Rotterdam, The Netherlands.

cDepartment of Epidemiology, Erasmus University Medical Centre, Rotterdam, The Netherlands.

${ }^{\mathrm{d}}$ Department of Pediatrics, Sophia Children's Hospital, Erasmus University Medical Centre, Rotterdam, The Netherlands.

All authors have completed and submitted the ICMJE Form for Disclosure of Potential Conflicts of Interest, and none were reported.

The Generation R. Study is made possible by financial support from the Erasmus Medical Center, Rotterdam, the Erasmus University Rotterdam and the Netherlands Organization for Health Research and Development. Research that
}

impaired dental function, and social disadvantage. ${ }^{2-4}$ Thus, correcting malocclusion has been advocated with the ultimate aim of improving overall well-being. To capture the extent to which malocclusion and its treatment affect the functioning and psychological has led to these findings received support by a Netherlands Organisation for Health Research and Development grant (VIDI 016.136.361), a European Research Council Consolidator Grant (ERC-2014-CoG-648916), and the European Union's Horizon 2020 research and innovation program under grant agreements No. 733206 (LifeCycle) and No. 633595 (DynaHEALTH).

Address correspondence to: Lea Kragt, Department of Oral and Maxillofacial Surgery, Erasmus University Medical Center, Special Dental Care and Orthodontics, PO Box 2040, Rotterdam 3000 CA, The Netherlands; e-mail, 1.kragt@ erasmusmc.nl.

Submitted, January 2019; revised and accepted, June 2019.

$0889-5406 / \$ 36.00$

(C) 2020 by the American Association of Orthodontists. All rights reserved.

https://doi.org/10.1016/j.ajodo.2019.06.015 
well-being of patients, oral health-related quality of life (OHRQOL) measures have been incorporated in orthodontic research. ${ }^{5}$ Children aged 8 years and older with severe malocclusion were more likely to experience a negative impact on their OHRQOL than those with normal occlusion. ${ }^{6-8}$ The negative impact of malocclusion on OHRQOL is also supported by 2 systematic literature reviews, yet high heterogeneity was observed among the studies. ${ }^{9,10}$ Individual malocclusion traits have demonstrated varying impacts on OHRQOL. ${ }^{11}$ Several studies have shown that children with an increased overjet experienced worse OHRQOL than those without. ${ }^{12-14}$ Orthodontic patients with a posterior crossbite also reported more impaired oral functions and psychological discomfort than those without. $^{15}$

Because malocclusion severity is determined by a collection of different deviant occlusal traits-including crowding, missing teeth, spacing between teeth, overjet, overbite, occlusion and skeletal relationship, crossbite, open bite, or eruption problems (eg, impacted teeth)the different collections of occlusal traits presented may have contributed to the heterogeneity in the association between malocclusion severity and OHRQOL. However, the influence of different malocclusion traits regarding orthodontic treatment need (OTN) has not been studied.

The overall aim of this project is to determine the impact of OTN on OHRQOL for children aged 10 years living in Rotterdam. The objectives of the study include (1) determining the impact of OTN on OHRQOL; (2) exploring whether sex, ethnicity or socioeconomic status modifies this impact of OTN on OHRQOL; and (3) exploring whether the impact of OTN on OHRQOL varies based on the presence of different malocclusion traits.

\section{MATERIAL AND METHODS}

This cross-sectional study was embedded in the Generation R. Study, a population-based, multiethnic prospective cohort study undertaken in Rotterdam, The Netherlands. Briefly, all pregnant women living within the study area with an expected delivery date between April 2002 and January 2006 were invited to participate in the study. Details of the study have been described elsewhere. ${ }^{16,17}$ The Generation R. Study has been approved by the Medical Ethical Committee of the Erasmus Medical Centre (MEC-2012-165), Rotterdam, The Netherlands.

Full consent for the postnatal phase of the Generation R Study was given for 7393 children aged 10 years. Information on OHRQOL was available for 3871 children. In addition, 3048 children had information on
OTN. Only 2714 of 3048 children had sufficient information on the presence of particular malocclusion traits. Thus, 3048 children were included in the main analysis, and 2714 children were included in the sub-analysis (Fig).

OHRQOL was assessed with a validated short version of the Child Oral Health Impact Profile (COHIP-Ortho). ${ }^{18}$ The COHIP-Ortho consists of 11 questions addressed to the parents of children. Parents have been shown to be good proxies for the assessment of children's OHRQOL. ${ }^{19,20}$ The COHIP-Ortho covers the different domains of oral health, such as social-emotional well-being, functional well-being, and school and peer interaction (Supplementary Table S1). The questions ask for oral health impacts of the past 3 months and are answered on a 5-point likert scale ranging from never (5) to almost all the time (1). The total overall score ranged from 11 to 55, in which a higher score indicated a higher OHRQOL. Missing values in the responses to questions of the COHIP-Ortho questionnaire were replaced by the individual's mean score of answers from the remaining questions. ${ }^{21}$ When more than $30 \%$ of the answers were missing, the participant was excluded from the analysis.

For the assessment of orthodontic treatment need and occlusal traits, the Index of Orthodontic Treatment Need (1OTN) was used. The Dental Health Component (DHC) and the Aesthetic Component (AC) of the IOTN were assessed using a combination of 2- and 3dimensional pictures with radiographs taken for all children who participated at the follow-up according to the cohort study protocol. Any incidental findings from the radiographs were reported and referred for further clinical management. This method has been validated for scientific studies, demonstrating fair reliability for the assessment of both 10TN grades and individual malocclusion traits. ${ }^{22}$ In the validation study, intrarater reliability was assessed using linear weighted kappa statistics and measured between $\kappa=0.66$ and $\kappa=0.68$, indicating good reproducibility of assessing the DHC grade with this method. The percentage of agreement ranged from $63.7 \%$ to $93.4 \%$ for different malocclusion traits. ${ }^{22}$ The DHC grade is determined with a hierarchical scale of malocclusion traits (Supplementary Table S2). ${ }^{23}$ The most severe of all malocclusion traits recorded indicates the final DHC grade for an individual, ranging from grade 1 to grade 5. Orthodontic treatment need is defined based on this score and is categorized as no need (Grade 1 and 2), borderline need (Grade 3), and definite need (Grade 4 and 5). ${ }^{23}$

An increased overjet of more than $3.5 \mathrm{~mm}$, reverse overjet of at least $0 \mathrm{~mm}$, crossbite of more than $0 \mathrm{~mm}$ between retruded contact position and intercuspal 


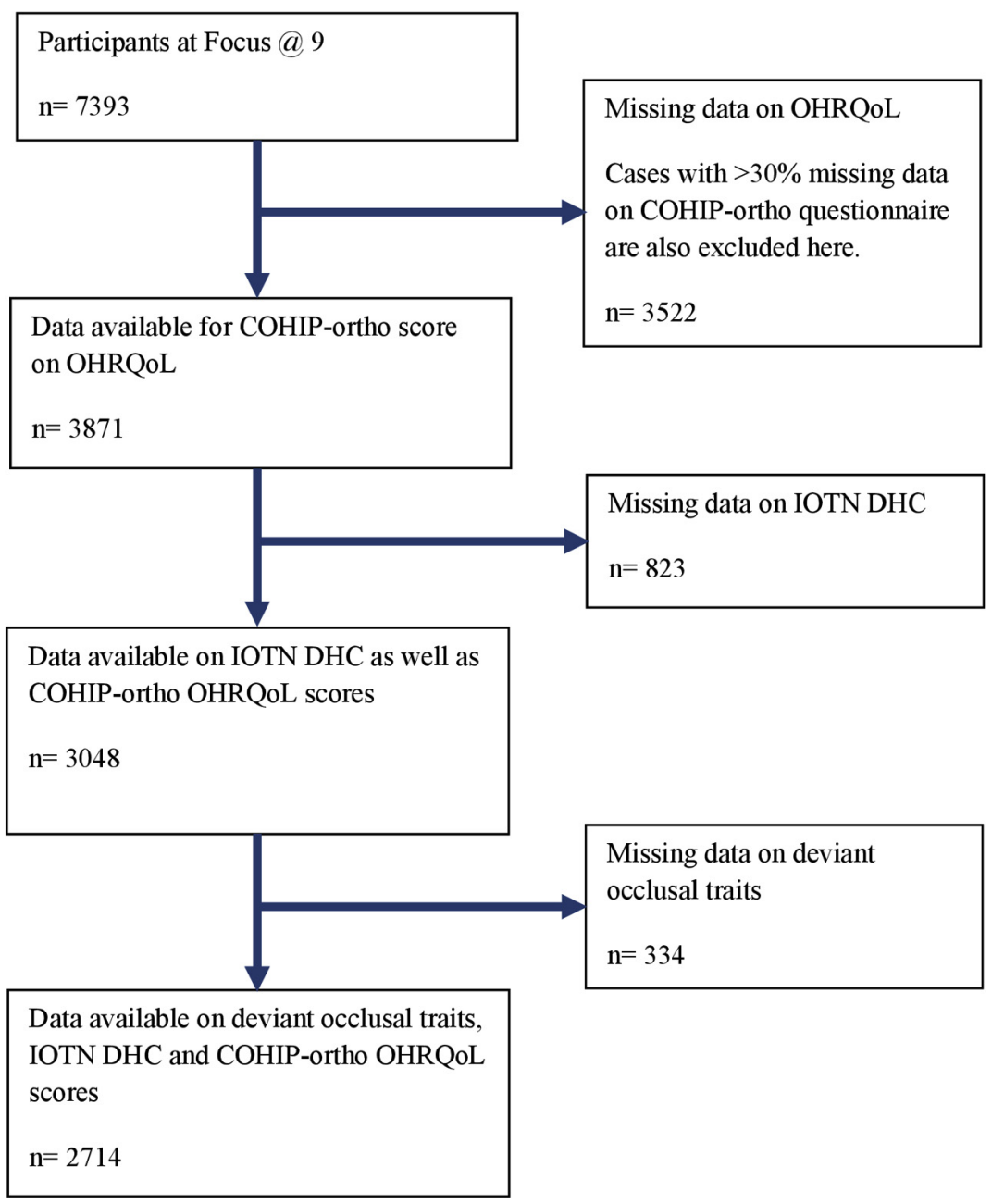

Fig. Study flow.

position, displacement of teeth of more than $1 \mathrm{~mm}$, open bite of at least $1 \mathrm{~mm}$, and overbite of at least $3.5 \mathrm{~mm}$ indicated the presence of respective malocclusion traits. ${ }^{23}$ Other traits such as missing teeth (hypodontia or impacted), posterior lingual crossbite, partially erupted teeth that are tipped and impacted, submerged deciduous teeth, and supplemental teeth were considered present if it involved at least 1 tooth. A good buccal occlusion was indicated when discrepancies found were less than half a unit. Intraexaminer and interexaminer error were assessed by authors (LK and EO) after 6 months on 50 cases from the present study. For these measurements, we calculated intrarater reliability (linear weighted $\kappa=0.84$ ) and interrater reliability (linear weighted $\kappa=0.68$ ). The AC is assessed based on a scale of 10 dental photographs of increasing esthetic impairment, categorized as no need (Grade 1-3), borderline need (Grade 4-6), and definite need (Grade 7-
10). In this study, AC was assessed by 1 calibrated examiner (LK).

Based on the previous literature, the following factors were considered as potential confounders for the association between OTN and OHRQOL, child's age, sex, socioeconomic status (SES), and ethnicity. Children's ethnicity was defined according to the Statistics Netherlands, based on the ethnic background of the child's parents. ${ }^{24}$ If both parents were born in the Netherlands, the child was classified as native Dutch. If at least 1 of the parents was not born in the Netherlands, the child was classified by the mother's ethnicity. The following SES indicators were used as potential confounders for the association between malocclusion and OHRQOL, education level of the parents (high vs low), net family household income $(\leq € 2400$ vs $>€ 2400)$, and single parenting (yes vs no). 
Table I. General characteristics of the study population by orthodontic treatment need $(n=3048)$

\begin{tabular}{|c|c|c|c|c|c|}
\hline \multirow[b]{2}{*}{ Characteristics } & \multicolumn{4}{|c|}{ OTN } & \multirow[b]{2}{*}{$\mathrm{P}$ value } \\
\hline & $\begin{array}{c}\text { No need } \\
n=1137 \\
(37.3 \%)\end{array}$ & $\begin{array}{c}\text { Borderline need } \\
n=765 \\
(25.1 \%)\end{array}$ & $\begin{array}{c}\text { Definite need } \\
n=1146 \\
(37.6 \%)\end{array}$ & $\begin{array}{c}\text { Total } \\
n=3048 \\
(100.0 \%)\end{array}$ & \\
\hline \multicolumn{6}{|l|}{ Child } \\
\hline Age, $\mathrm{y}^{\dagger}$ & $9.74(9.5-10.1)$ & $9.73(9.5-10.0)$ & $9.74(9.5-10.0)$ & $9.74(9.5-10.0)$ & 0.336 \\
\hline $\operatorname{Sex}(\%)$ & & & & & 0.273 \\
\hline Male & $587(19.3)$ & $369(12.1)$ & $561(18.4)$ & $1517(49.7)$ & \\
\hline Female & $550(18.0)$ & $396(13.0)$ & $585(19.2)$ & $1531(50.2)$ & \\
\hline Ethnicity $(\%)^{\ddagger}$ & & & & & 0.946 \\
\hline Dutch & $766(25.1)$ & $515(16.9)$ & $764(25.1)$ & $2045(67.1)$ & \\
\hline Non-Dutch & $362(11.9)$ & $247(8.1)$ & $372(12.2)$ & $981(32.2)$ & \\
\hline 10TN-AC $(\%)^{\S}$ & & & & & $<0.001$ \\
\hline No and little need & 943 (30.9) & $440(14.4)$ & $308(10.1)$ & $1691(55.5)$ & \\
\hline Borderline need & $112(3.8)$ & $319(10.5)$ & 575 (18.9) & $1006(33.0)$ & \\
\hline Definite need & $0(0)$ & $3(0.1)$ & $244(8.0)$ & $247(8.4)$ & \\
\hline COHIP-Ortho score ${ }^{*}$ & $50.00(46.00-52.00)$ & $50.00(45.00-52.00)$ & $49.00(43.00-51.00)$ & $50.00(45.00-52.00)$ & $<0.001$ \\
\hline Missing teeth $(\%)^{\S}$ & & & & & $<0.001$ \\
\hline No missing teeth & $1102(36.2)$ & $743(24.4)$ & $761(25.0)$ & 2606 (85.5) & \\
\hline Hypodontia & $0(0.0)$ & $0(0.0)$ & $163(5.3)$ & $163(5.3)$ & \\
\hline Impacted & $0(0.0)$ & $0(0.0)$ & $201(6.6)$ & $201(6.6)$ & \\
\hline Overjet $(\%)^{\S}$ & & & & & $<0.001$ \\
\hline None & $758(24.9)$ & $450(14.8)$ & $508(16.7)$ & $1716(56.3)$ & \\
\hline Increased overjet & $344(11.3)$ & $277(9.1)$ & $595(19.5)$ & $1216(39.9)$ & \\
\hline Reverse overjet & $12(0.4)$ & $24(0.8)$ & $32(1.0)$ & $68(2.2)$ & \\
\hline Crossbite $(\%)^{\S}$ & & & & & $<0.001$ \\
\hline None & 849 (27.9) & $447(14.7)$ & 699 (22.9) & 1995 (65.5) & \\
\hline Crossbite & $156(5.1)$ & $279(9.2)$ & $392(12.9)$ & $827(27.1)$ & \\
\hline Displacement $(\%)^{\S}$ & & & & & $<0.001$ \\
\hline None & $248(8.1)$ & $50(1.6)$ & $91(3.0)$ & 389 (12.8) & \\
\hline Displacement & $805(26.4)$ & $714(23.4)$ & $1030(33.8)$ & 2549 (83.6) & \\
\hline Overbite $(\%)^{\S}$ & & & & & $<0.001$ \\
\hline None & $806(26.4)$ & $420(13.8)$ & 691 (22.7) & 1917 (62.9) & \\
\hline Open bite & $61(2.0)$ & $88(2.9)$ & $133(4.4)$ & $282(9.3)$ & \\
\hline Overbite & $165(5.4)$ & 241 (7.9) & $286(9.4)$ & $692(22.7)$ & \\
\hline Other $(\%)^{\S}$ & & & & & $<0.001$ \\
\hline No other traits & $319(10.5)$ & $472(15.5)$ & $635(20.8)$ & $1426(46.8)$ & \\
\hline $\begin{array}{l}\text { Good buccal } \\
\text { occlusion }\end{array}$ & $679(22.3)$ & $252(8.3)$ & $304(10.0)$ & $1235(40.5)$ & \\
\hline $\begin{array}{l}\text { Posterior lingual } \\
\text { crossbite }\end{array}$ & $0(0.0)$ & $0(0.0)$ & $7(0.2)$ & $7(0.2)$ & \\
\hline Submerged teeth & $0(0.0)$ & $0(0.0)$ & $0(0.0)$ & $0(0.0)$ & \\
\hline $\begin{array}{l}\text { Partially } \\
\text { erupted teeth }\end{array}$ & $0(0.0)$ & $0(0.0)$ & $131(4.3)$ & $131(4.3)$ & \\
\hline Supernumerary teeth & $0(0.0)$ & $0(0.0)$ & $12(0.4)$ & $12(0.4)$ & \\
\hline \multicolumn{6}{|l|}{ Parent } \\
\hline $\begin{array}{c}\text { Maternal educational } \\
\text { level }(\%)^{\ddagger, \Phi}\end{array}$ & & & & & 0.340 \\
\hline Low & $381(12.5)$ & $230(7.5)$ & $371(12.2)$ & $982(32.2)$ & \\
\hline High & $693(22.7)$ & $483(15.8)$ & $689(22.6)$ & $1865(61.1)$ & \\
\hline $\begin{array}{l}\text { Paternal education } \\
\text { level }(\%)^{\ddagger},\end{array}$ & & & & & 0.478 \\
\hline Low & $381(12.5)$ & $237(7.8)$ & $352(11.5)$ & $970(31.8)$ & \\
\hline High & $625(21.4)$ & $433(14.2)$ & $635(20.8)$ & $1693(55.5)$ & \\
\hline $\begin{array}{l}\text { Net household } \\
\text { income }(\%)^{\ddagger}\end{array}$ & & & & & 0.735 \\
\hline$<€ 2000$ & $177(5.8)$ & $110(3.6)$ & $163(5.3)$ & $450(14.8)$ & \\
\hline$€ 2000-€ 3200$ & $248(8.1)$ & $176(5.8)$ & $273(9.0)$ & 697 (22.9) & \\
\hline$>€ 3200$ & 596 (19.6) & $400(13.1)$ & $586(19.2)$ & $1582(51.9)$ & \\
\hline
\end{tabular}




\begin{tabular}{|c|c|c|c|c|c|}
\hline \multirow[b]{3}{*}{ Characteristics } & \multicolumn{4}{|c|}{ OTN } & \multirow{4}{*}{$\begin{array}{c}\text { P value* } \\
0.382\end{array}$} \\
\hline & & & & & \\
\hline & (37.3\%) & (25.1\%) & (37.6\%) & (100.0\%) & \\
\hline \multicolumn{5}{|l|}{ Family composition $(\%)^{\ddagger, \#}$} & \\
\hline One parent & $946(31.0)$ & $641(21.0)$ & $953(31.3)$ & $2540(83.3)$ & \\
\hline Two parents & $124(4.1)$ & $70(2.3)$ & $106(3.5)$ & $300(9.8)$ & \\
\hline \multicolumn{6}{|c|}{ 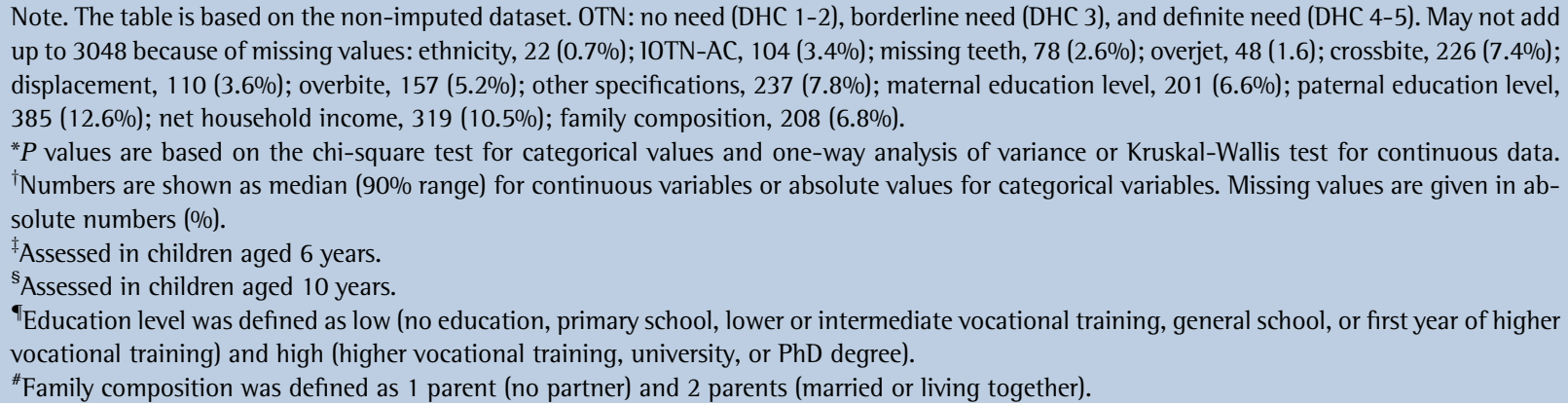 } \\
\hline
\end{tabular}

\section{Statistical analysis}

Statistical analyses were performed with SPSS software version 21 (IBM, Armonk, NY). Descriptive statistics were used to characterize the study population. Differences in child and parental characteristics among OTN groups were evaluated with the chi-square tests, oneway analysis of variance, and Kruskal-Wallis tests.

To test the associations between OTN and OHRQOL, we built multiple linear regression models with weighted least squares. Three different models were created with OTN as the main determinant and the COHIP-Ortho score as the primary outcome. The first model was adjusted for the child's age and sex. In addition, the second model was adjusted for SES indicators and ethnicity, whereas the third model was adjusted for the AC.

We tested for effect modification by sex, ethnicity, and $A C$ in the association of OTN and OHRQOL by including the respective interaction terms in the crude model. A significant interaction was observed for sex, and thus, we analyzed the association between OTN and OHRQOL stratified by sex.

To test the associations between the individual malocclusion traits and OHRQOL, we performed a similar series of the before mentioned regression models. The presence of missing teeth (hypodontia or impacted), increased overjet, reverse overjet, crossbite, displacement of teeth, and overjet were included 1 by 1 as an independent variable in model 1 , and in model 2 all occlusal traits were included simultaneously as independent variables. In addition, model 3 was adjusted for overall OTN (DHC grade). Other traits, including good occlusion, posterior lingual crossbite, submerged deciduous teeth, partially erupted or tilted teeth, and supernumerary teeth were not individually analyzed because of insufficient numbers.

Multiple imputations were performed to deal with the missing values of covariates using the Markov Chain Monte Carlo method. In total, 5 independent data sets with a fully conditional specified model were generated and used to calculate the pooled effect estimates (adjusted betas [a $\beta$ ] with 95\% confidence intervals [CI]). Imputations were based on the associations between all variables used in this study, but the missing values from the main exposure (OTN) and outcome (COHIP-Ortho scores) were not imputed.

\section{RESULTS}

A total of 3048 children participated in this study. Table 1 shows the individual and family characteristics of the study population by OTN. There was a slight majority of children (37.6\%) that had definite OTN, whereas 25.1\% of children had borderline $0 T N$, and $37.3 \%$ of children had no OTN. The median (90\% range) OHRQOL score of children aged 10 years was 50.0 (45.0-52.0). The AC and presence of malocclusion traits, including missing teeth, overjet, crossbite, displacement of teeth, overbite, and others varied significantly between children with a different need for orthodontic treatment $(P<0.001)$.

Table 11 shows associations of OTN and OHRQoL analyzed overall and stratified by sex. A significant inverse association between OTN and OHRQOL was observed based on model 1 (definite need: $\mathrm{a} \beta=-1.27 ; 95 \% \mathrm{Cl}-1.53$ to -1.01 and borderline need: $a \beta=-0.45 ; 95 \% \mathrm{Cl}-0.71$ to -0.20$)$. In 
Table II. Associations of orthodontic treatment need and OHRQOL in children aged 10 years analyzed overall and stratified by sex $(n=3048)$

\begin{tabular}{|c|c|c|c|c|}
\hline \multirow[b]{2}{*}{ Orthodontic treatment need } & \multirow[b]{2}{*}{$n$} & \multicolumn{3}{|c|}{ OHRQOL score, $\beta$ (95\% CI) } \\
\hline & & Total $(n=3048)$ & Boys $(n=1517)$ & Girls $(n=1531)$ \\
\hline No need & 1137 & Reference & Reference & Reference \\
\hline Borderline need & 765 & & & \\
\hline Crude & & $-0.51(-0.78,-0.24)^{\dagger}$ & $-0.47(-0.85,-0.10)$ & $-0.57(-0.95,-0.19)$ \\
\hline Model $1^{\ddagger}$ & & $-0.45(-0.71,-0.20)^{\S}$ & $-0.38(-0.74,-0.02)$ & $-0.54(-0.91,-0.16)$ \\
\hline Model 2 & & $-0.34(-0.61,-0.08)^{\S}$ & $-0.29(-0.65,0.07)$ & $-0.45(-0.84,-0.06)$ \\
\hline Definite need & 1146 & & & \\
\hline Crude & & $-1.34(-1.60,-1.07)^{\dagger}$ & $-1.03(-1.38,-0.67)$ & $-1.70(-2.10,-1.31)$ \\
\hline Model $1^{\ddagger}$ & & $-1.27(-1.53,-1.01)^{\dagger}$ & $-0.97(-1.31,-0.63)$ & $-1.63(-2.02,-1.25)$ \\
\hline Model 2 & & $-0.81(-1.12,-0.50)$ & $-0.57(-0.96,-0.17)$ & $-1.21(-1.68,-0.73)$ \\
\hline$P$ linear trend ${ }^{\#}$ & & $<0.001$ & $<0.001$ & $<0.001$ \\
\hline$P$ interaction & & & & 0.012 \\
\hline $\begin{array}{l}{ }^{*} \text { Crude model is adjusted for } \\
{ }^{\dagger} \text { Statistical significance at } P< \\
{ }^{\ddagger} \text { Model } 1 \text { is adjusted for ethn } \\
\text { education (low vs high), and } \\
\text { SStatistical significance at } P< \\
{ }^{\top} \text { Model } 2 \text { is adjusted for } 10 T \\
{ }^{*} P \text { for trend for the fully adju }\end{array}$ & $\begin{array}{l}\text { and ag } \\
\text { tch vs } r \\
\text { tatus ( }\end{array}$ & $\begin{array}{l}\text { otal sample, and only ag } \\
\text { h), net household incom } \\
\text { living together vs no pa }\end{array}$ & $\begin{array}{l}\text { ratified by sex. } \\
0,>€ 2400) \text {, mother's }\end{array}$ & (low vs high), father's \\
\hline
\end{tabular}

addition, when adjusted for the $\mathrm{AC}$ in model 2, the association between OTN and OHRQOL was attenuated but remained significant (definite need: $a \beta=-0.81$; $95 \% \mathrm{Cl}-1.12$ to -0.50 and borderline need: $\mathrm{a} \beta=-0.34 ; 95 \% \mathrm{Cl}-0.61$ to -0.08$)$. Moreover, in model 2, AC itself was found to have a significant negative association with OHRQOL $(\mathrm{a} \beta=-0.74 ; 95 \% \mathrm{Cl}$ -1.08 to -0.40 ).

The influence of OTN on OHRQOL appeared to be modified by the sex of the child. In the fully adjusted model, the impact of definite OTN was more than double in girls than in boys $(\mathrm{a} \beta=-1.21 ; 95 \% \mathrm{Cl}-1.68,-0.73$ and $\mathrm{a} \beta=-0.57 ; 95 \% \mathrm{Cl}-0.96$ to -0.17 , respectively). The difference between boys and girls was significant $(P=0.012)$.

All of the various occlusal traits were negatively associated with OHRQOL; however, these associations were only significant for impacted tooth $(\mathrm{a} \beta=-0.91 ; 95 \%$ $\mathrm{Cl}-1.46$ to -0.35$)$, increased overjet $(\mathrm{a} \beta=-0.41$; $95 \% \mathrm{Cl}-0.65$ to -0.18 ), and displacement of teeth ( $\mathrm{a} \beta=-0.54 ; 95 \% \mathrm{Cl}-0.80$ to -0.16 ; model 1 , Table 111). An impacted tooth had the greatest negative impact on OHRQOL $(\mathrm{a} \beta=-1.07 ; 95 \% \mathrm{Cl}-1.65$ to -0.49 ; model 2, Table 111) after taking other occlusal traits into account. However, when adjusted for the severity of OTN, only the overjet remained to have a significant negative impact on OHRQOL $(\mathrm{a} \beta=-0.26 ; 95 \% \mathrm{Cl}$ -0.50 to -0.02 ; model 3, Table 111). Thus, an overjet lowers OHRQOL independent of whether it should be orthodontically treated.

\section{DISCUSSION}

The results show that OTN is negatively associated with OHRQOL in 10-year-old children. Greater OTN has a stronger negative impact on OHRQOL in girls than in boys. Of the malocclusion traits considered in this study, only impacted teeth, an increased overjet, and displacement of teeth have a consistently negative impact on a child's OHRQOL.

An inverse relationship between the severity of malocclusion measured by OTN and OHRQOL was found in this study. This finding was expected as other studies have shown similar results. ${ }^{6-8}$ Moreover, this study showed that the negative impact on OHRQOL was progressively greater with an increasing degree of OTN. Not only did having definite OTN decrease OHRQOL, but having borderline OTN also significantly decreased OHRQOL. This study revealed that although minor malocclusions may not constitute a professionally determined need for orthodontic treatment, parents already perceive the negative impact on their child's OHRQOL. In line with this finding, a survey of Dutch parents showed that 56\% of the parents considered orthodontic treatment to be necessary for their child, a percentage that was much higher than the percentage of children with definite OTN in this sample. 'Mild malocclusions are generally not completely associated with any functional impairment but have been associated with esthetic impairment. ${ }^{4,25}$

In the present study, OTN did not significantly differ by sex, ethnicity, or SES. However, sex appeared to have 
Table III. Association of the presence of individual occlusal traits (from Grade 2 onwards) and OHRQOL in children aged 10 years $(n=2714)$

\begin{tabular}{|c|c|c|c|c|c|}
\hline \multirow{2}{*}{$\begin{array}{l}\text { Individual trait } \\
\text { components } \\
\text { of IOTN-DHC }\end{array}$} & \multirow[b]{2}{*}{$n$} & \multicolumn{4}{|c|}{ OHRQOL score $\beta(95 \% \mathrm{CI})$} \\
\hline & & Crude model ${ }^{*}$ & Model $1^{\dagger}$ & Model $2^{\ddagger}$ & Model $3^{\mathcal{S}}$ \\
\hline \multicolumn{6}{|l|}{ Missing teeth } \\
\hline None & 2606 & Reference & Reference & Reference & Reference \\
\hline Hypodontia & 163 & $-0.11(-0.61,0.39)$ & $-0.17(-0.67,0.33)$ & $-0.12(-0.59,0.35)$ & $0.58(0.06,1.10)^{\#}$ \\
\hline lmpacted & 201 & $-0.98(-1.53,-0.43)^{\#}$ & $-0.91(-1.46,-0.35)^{\#}$ & $-1.07(-1.65,-0.49)$ & $-0.41(-1.00,0.19)$ \\
\hline \multicolumn{6}{|l|}{ Overjet } \\
\hline None & 1716 & Reference & Reference & Reference & Reference \\
\hline Increased overjet & 1216 & $-0.46(-0.70,-0.23)$ & $-0.41(-0.65,-0.18)^{*}$ & $-0.48(-0.73,-0.24)$ & $-0.26(-0.50,-0.02)^{\#}$ \\
\hline Reverse overjet & 68 & $-0.29(-1.15,0.58)$ & $-0.39(-1.23,0.46)$ & $-0.45(-1.36,0.46)$ & $-0.22(-1.10,0.67)$ \\
\hline \multicolumn{6}{|l|}{ Crossbite } \\
\hline None & 1995 & Reference & Reference & Reference & Reference \\
\hline Crossbite & 827 & $-0.33(-0.61,-0.06)^{\#}$ & $-0.24(-0.55,0.03)$ & $-0.26(-0.53,0.02)$ & $-0.07(-0.34,0.20)$ \\
\hline \multicolumn{6}{|l|}{ Displacement } \\
\hline None & 389 & Reference & Reference & Reference & Reference \\
\hline Displacement & 2549 & $-0.54(-0.86,-0.22)^{\#}$ & $-0.48(-0.80,-0.16)^{\#}$ & $-0.36(-0.69,-0.03)^{\#}$ & $-0.10(-0.41,0.22)$ \\
\hline \multicolumn{6}{|l|}{ Overbite } \\
\hline None & 1917 & Reference & Reference & Reference & Reference \\
\hline Open bite & 282 & $-0.20(-0.62,0.22)$ & $-0.19(-0.59,0.22)$ & $-0.12(-0.53,0.30)$ & $-0.05(-0.46,0.36)$ \\
\hline Overbite & 692 & $-0.19(-0.47,0.09)$ & $-0.22(-0.49,0.06)$ & $-0.19(-0.47,0.10)$ & $-0.07(-0.35,0.21)$ \\
\hline \multicolumn{6}{|c|}{ 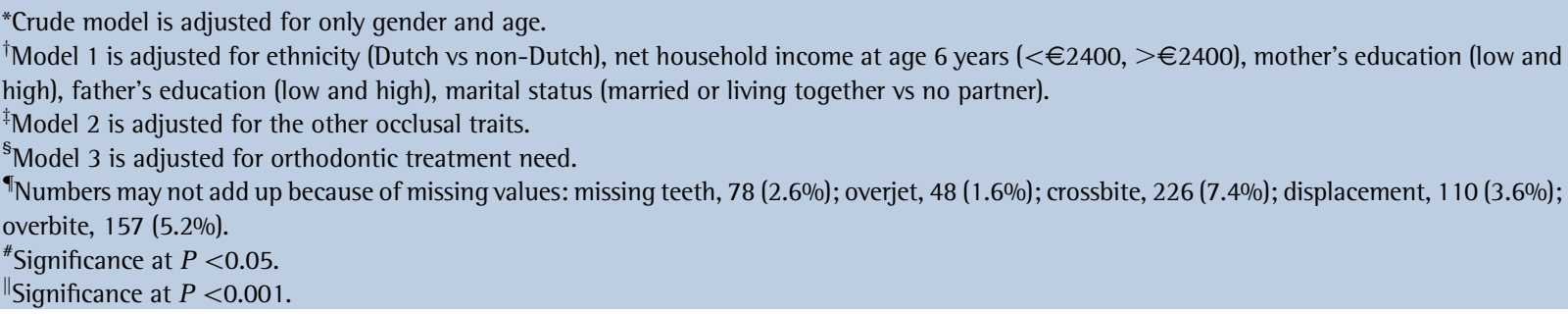 } \\
\hline
\end{tabular}

a differential effect on the relationship between OTN and OHRQOL. Girls who have borderline or definite OTN reported worse OHRQOL than boys with the same OTN. It has been observed in previous literature that girls generally report poorer OHRQOL than boys. ${ }^{26,27}$ As the onset of puberty in girls is earlier than in boys, girls aged 10 years may already start to be more selfconscious of their malocclusion. Another study reported that girls aged 8-11 years were more critical of their smiles than boys, and therefore, had a higher perceived need for orthodontic treatment as well. ${ }^{28}$ In a sample of Dutch children aged 8-12 years, girls were more likely to have lower self-esteem than boys. ${ }^{29}$ Children with low self-esteem, in turn, experience a greater impact of malocclusions on OHRQOL than those without low selfesteem. ${ }^{30}$ Thus, the difference between girls and boys in the association of OTN and OHRQOL might also be partly mediated by self-esteem. ${ }^{27}$

A comparison of the influence of different malocclusion traits on OHRQOL revealed that the presence of an impacted tooth, increased overjet, and displacement of teeth was significantly associated with lower OHRQOL. Based on previous literature, the negative impact of an overjet on OHRQOL has been well established. ${ }^{12,25}$ The overjet is a conspicuous occlusal trait because of its anterior location and is likely to contribute to esthetic and functional impairment, and thus, OHRQOL. However, the negative association between having an impacted tooth and OHRQOL appeared to be even stronger after adjusting for other malocclusion traits. In the present study, the impacted teeth were most commonly the maxillary canines. The anterior location of the canine ensures its frequent visibility to the child or parent. An impacted canine may present as a spacing in the occlusion or a severely displaced buccal or palatal eruption of the tooth. Hence, the location and presentation of the impaction in the esthetic zone may reinforce the negative influence on the evaluation of the child's OHRQOL. When adjusted for other traits, hypodontia, reverse overjet, open bite, increased overbite, and crossbite did not have any significant impact on OHRQOL. The lack of significant effects of these traits in our study might be explained by a relatively low prevalence in the current sample. However, a study on Finnish adults also showed no significant effects of crossbite and increased overbite or open bite on OHRQOL. ${ }^{25}$ 
In this study, the severity of malocclusion was assessed using the 10TN. The 10TN grade was determined using a combination of 2- and 3-dimensional pictures with radiographs, without any clinical examination. Although the method was suitable for determining OTN in general, the reliability of assessing individual grades of malocclusion traits was only fair. ${ }^{22}$ In addition, the presence of an occlusal trait was considered present from grade 2 and above, which might have led to misclassification of certain traits. Misclassification of the determinant might have weakened the association presented in this study.

Because of the logistical constraints of the cohort study, the information on the child's OHRQOL was collected using a parental questionnaire. Ideally, OHRQOL should be self-assessed by the children for an accurate understanding of their oral health well-being. However, children's understanding of their oral health is limited by their social, lingual, emotional, and cognitive development, making the development of appropriate OHRQOL measures for children very challenging. Therefore, although the use of a parental questionnaire is a limitation, it has been suggested that parents are valid proxies for the assessment of their child's OHRQOL in the context of orthodontics. ${ }^{19,20}$ Future studies should assess agreement between self and parental reported OHRQOL of children aged 10 years. Finally, this study excluded a large number of participants because of incomplete information. This factor could have resulted in some selection bias if those excluded had a different association between OTN and OHRQOL than those included. However, no significant differences in the outcome were observed in the nonresponse analysis (Supplementary Table S3).

The major strength of the study is the use of a large population-based cohort of ethnically diverse children. The large sample size allowed consideration of many different occlusal traits and a broad range of malocclusion severity.

The present results provide generalizable findings of the negative impact of malocclusions on OHRQOL in children aged 10 years before the start of orthodontic treatment. Longitudinal assessment of the impact of malocclusion on OHRQOL, the eventual uptake of orthodontic treatment, and associated changes in OHRQOL need to be studied in the future. The IOTN has been used routinely to determine individuals who are eligible to receive subsidized orthodontic treatment based on the professional judgment of treatment needs. ${ }^{23}$ This study has shown that children with mild malocclusion still experience negative impacts on their quality of life. In addition, this negative impact can be greater if the malocclusion trait is in the esthetic zone of the dentition. In this study, we have chosen not to focus on psychological factors that may mediate malocclusion and OHRQOL, as it goes beyond the scope of the study objectives. Further research should explore the role of low self-esteem and other psychological factors in the association between visible malocclusion traits and OHRQOL. Findings of the present and also future studies should be used to facilitate health policy strategies to decrease the burden of malocclusion in the population.

\section{CONCLUSIONS}

The severity of malocclusion, as measured through the 10TN, has a negative impact on OHRQOL in children aged 10 years. With the same level of malocclusion severity, girls are more likely to experience lower OHRQOL than boys. Although OTN is determined through the objective measurement of malocclusion traits, this study showed that the impact of different traits is unlikely to be comparable. The presence of an impacted canine increased overjet, and displacement of teeth are more likely to have a significant impact on OHRQOL than other malocclusion traits.

\section{ACKNOWLEDGMENTS}

The authors thank the participants, general practitioners, hospitals, midwives, and pharmacies in Rotterdam, the Netherlands.

\section{SUPPLEMENTARY DATA}

Supplementary data associated with this article can be found, in the online version, at https://doi.org/10. 1016/j.ajodo.2019.06.015.

\section{REFERENCES}

1. Schuller A, Poorterman J, van Kempen C, Dusseldorp E, Dommelen Pv, Verrips G. Kies voor tanden. Een onderzoek naar mondgezondheid en preventief tandheelkundig gedrag van jeugdigen. Tussenmeting 2009, een vervolg op de reeks TJZ-onderzoeken (Opt for teeth. A research on oral health and preventive dental behavior of juveniles. Interim measurement 2009, a continuation of the series of TJZ studies). TNO; 2011.

2. Kerosuo H, Hausen H, Laine T, Shaw WC. The influence of incisal malocclusion on the social attractiveness of young adults in Finland. Eur J Orthod 1995;17:505-12.

3. Feldens CA, Dos Santos Dullius Al, Kramer PF, Scapini A, Busato AL, Vargas-Ferreira F. Impact of malocclusion and dentofacial anomalies on the prevalence and severity of dental caries among adolescents. Angle Orthod 2015;85:1027-34.

4. Bourdiol P, Soulier-Peigue D, Lachaze P, Nicolas E, Woda A, Hennequin M. Only severe malocclusion correlates with mastication deficiency. Arch Oral Biol 2017;75:14-20.

5. De Oliveira CM, Sheiham A. The relationship between normative orthodontic treatment need and oral health-related quality of life. Commun Dent Oral Epidemiol 2003;31:426-36. 
6. Sardenberg F, Martins MT, Bendo CB, Pordeus IA, Paiva SM, Auad SM, et al. Malocclusion and oral health-related quality of life in Brazilian school children. Angle Orthod 2013;83:83-9.

7. Aguilar-Díaz FC, lrigoyen-Camacho ME, Borges-Yáñez SA. OralHealth-related quality of life in schoolchildren in an endemic fluorosis area of Mexico. Qual Life Res 2011;20:1699-706.

8. Schuch HS, Costa Fdos S, Torriani DD, Demarco FF, Goettems ML. Oral Health-related quality of life of schoolchildren: impact of clinical and psychosocial variables. Int J Paediatr Dent 2015;25: 358-65.

9. Kragt L, Dhamo B, Wolvius EB, Ongkosuwito EM. The impact of malocclusions on oral health-related quality of life in children-a systematic review and meta-analysis. Clin Oral Investig 2016;20: 1881-94.

10. Zhang M, McGrath C, Hägg U. The impact of malocclusion and its treatment on quality of life: a literature review. Int J Paediatr Dent 2006;16:381-7.

11. Masood M, Suominen AL, Pietila T, Lahti S. Malocclusion traits and oral health-related quality of life in Finnish adults. Commun Dent Oral Epidemiol 2017;45:178-88.

12. Seehra J, Fleming PS, Newton T, DiBiase AT. Bullying in orthodontic patients and its relationship to malocclusion,self-esteem and oral health-related quality of life. J Orthod 2011;38:247-56; quiz 294.

13. Johal A, Cheung MY, Marcene W. The impact of two different malocclusion traits on quality of life. Br Dent J 2007;202:E2.

14. Obilade OA, Sanu 00, Costa 00. Impact of three malocclusion traits on the quality of life of orthodontic patients. Int Orthod 2016;14:366-85.

15. Masood M, Masood Y, Newton T. Cross-bite and oral health related quality of life in young people. J Dent 2014;42:249-55.

16. Kruithof CJ, Kooijman MN, van Duijn CM, Franco OH, de Jongste JC, Klaver CC, et al. The Generation R Study: biobank update 2015. Eur J Epidemiol 2014;29:911-27.

17. Kooijman MN, Kruithof CJ, van Duijn CM, Duijts L, Franco OH, van 1Jzendoorn MH, et al. The Generation R Study: design and cohort update 2017. Eur J Epidemiol 2016;31:1243-64.

18. Kragt L, Tiemeier H, Wolvius EB, Ongkosuwito EM. Measuring oral health-related quality of life in orthodontic patients with a short version of the Child Oral Health Impact Profile (COHIP). J Public Health Dent 2016;76:105-12.
19. Bos A, Hoogstraten J, Zentner A. Perceptions of Dutch orthodontic patients and their parents on oral health-related quality of life. Angle Orthod 2010;80:367-72.

20. Wilson-Genderson M, Broder HL, Phillips C. Concordance between caregiver and child reports of children's oral health-related quality of life. Commun Dent Oral Epidemiol 2007;35(Suppl 1):32-40.

21. Geels LM, Hoogstraten J, Prahl-Andersen B. Confirmative factor analysis of the dimensions of the Child Oral Health Impact Profile (Dutch version). Eur J Oral Sci 2008;116:148-52.

22. Kragt L, Hermus AM, Wolvius EB, Ongkosuwito EM. Three-dimensional photographs for determining the Index of Orthodontic Treatment Need in scientific studies. Am J Orthod Dentofacial Orthop 2016;150:64-70.

23. Brook PH, Shaw WC. The development of an index of orthodontic treatment priority. Eur J Orthod 1989;11:309-20.

24. Swertz 0, Duimelaar P, Thijssen J. Migrants in the Netherlands 2004. Voorburg/Heerlen, The Netherlands: Statistics Netherlands; 2004.

25. Sierwald 1, John MT, Schierz O, Jost-Brinkmann PG, Reissmann DR. Association of overjet and overbite with esthetic impairments of oral health-related quality of life. J Orofac Orthop 2015;76:405-20.

26. Ghijselings 1, Brosens V, Willems G, Fieuws S, Clijmans M, Lemiere J. Normative and self-perceived orthodontic treatment need in 11- to 16-year-old children. Eur J Orthod 2014;36: $179-85$.

27. Kragt L, Jaddoe V, Wolvius E, Ongkosuwito E. The association of subjective orthodontic treatment need with oral healthrelated quality of life. Commun Dent Oral Epidemiol 2017;45: 365-71.

28. Christopherson EA, Briskie D, Inglehart MR. Objective, subjective, and self-assessment of preadolescent orthodontic treatment need-A function of age, gender, and ethnic/racial background? J Public Health Dent 2009;69:9-17.

29. Van Dongen-Melman JEWM, Koot HM, Verhulst FC. Cross-cultural validation of Harter's self-perception profile for children in a Dutch sample. Educ Psychol Meas 1993;53:739-53.

30. Agou S, Locker D, Streiner DL, Tompson B. Impact of self-esteem on the Oral-Health-related quality of life of children with malocclusion. Am J Orthod Dentofacial Orthop 2008;134: 484-9. 
Niue et al

772.e1

Supplementary Table S1. The 11 items of the COHIP-Ortho used in the current study

During the past 3 months, how often has your child:

1. Had pain and/or toothache in his or her teeth.

2. Had crooked teeth or spaces between his or her teeth.

3. Had discolored teeth or spots on his or her teeth.

4. Had bad breath.

5. Had bleeding gums.

6. Had difficulty eating foods he or she would like to because of his or her teeth, mouth or face.

7. Felt worried or anxious because of his or her teeth, mouth or face.

8. Not wanted to speak and/or read out loud in class because of his or her teeth, mouth or face.

9. Been teased, bullied or called names by other children because of his or her teeth, mouth or face.

10. Felt that he or she was attractive (good-looking) because of his or her teeth, mouth or face.

11. Had difficulty saying certain words because of his or her teeth or mouth.

American Journal of Orthodontics and Dentofacial Orthopedics

June $2020 \bullet$ Vol $157 \bullet$ Issue 6 


\section{Supplementary Table S2. The DHC of the IOTN}

\begin{tabular}{|c|c|c|}
\hline \multicolumn{2}{|l|}{ Grade } & Component \\
\hline \multirow[t]{6}{*}{ Grade 5 (very great) } & a & Increased overjet of more than $9 \mathrm{~mm}$. \\
\hline & $\mathrm{h}$ & $\begin{array}{l}\text { Extensive hypodontia with restorative implications (more than } 1 \text { tooth missing in any quadrant) requiring } \\
\text { prerestorative orthodontics. }\end{array}$ \\
\hline & i & $\begin{array}{l}\text { Impeded eruption of teeth (except for third molars) because of crowding, displacement, the presence of } \\
\text { supernumerary teeth, retained deciduous teeth, and any pathological cause. }\end{array}$ \\
\hline & $\mathrm{m}$ & Reverse overjet greater than $3.5 \mathrm{~mm}$ with reported functional difficulties. \\
\hline & $\mathrm{p}$ & Defects of cleft lip and palate. \\
\hline & $\mathrm{s}$ & Submerged deciduous teeth. \\
\hline \multirow[t]{11}{*}{ Grade 4 (great) } & a & Increased overjet more than $6 \mathrm{~mm}$ but less than or equal to $9 \mathrm{~mm}$. \\
\hline & $\mathrm{b}$ & Reverse overjet more than $3.5 \mathrm{~mm}$ with no functional difficulties. \\
\hline & c & $\begin{array}{l}\text { Anterior or posterior crossbite with more than a } 2-\mathrm{mm} \text { discrepancy between retruded contact position and } \\
\text { intercuspal position. }\end{array}$ \\
\hline & d & Severe displacements of teeth more than $4 \mathrm{~mm}$. \\
\hline & e & Extreme lateral or anterior open bites more than $4 \mathrm{~mm}$. \\
\hline & f & Increased and complete overbite with labial of palatal trauma. \\
\hline & $\mathrm{h}$ & Less extensive hypodontia ( 1 tooth missing per quadrant) requiring prerestorative orthodontics. \\
\hline & 1 & Posterior lingual crossbite with no functional occlusal contact in 1 or both buccal segments. \\
\hline & $\mathrm{m}$ & Reverse overjet greater than $1 \mathrm{~mm}$ but less than $3.5 \mathrm{~mm}$ with reported functional difficulties. \\
\hline & $\mathrm{t}$ & Partially erupted teeth, tipped, and impacted against adjacent teeth. \\
\hline & $\mathrm{x}$ & Supplemental teeth. \\
\hline \multirow[t]{6}{*}{ Grade 3 (moderate) } & a & Increased overjet more than $3.5 \mathrm{~mm}$ but less than or equal to $6 \mathrm{~mm}$ with incompetent lips. \\
\hline & $\mathrm{b}$ & Reverse overjet greater than $1 \mathrm{~mm}$ but less than or equal to $3.5 \mathrm{~mm}$. \\
\hline & c & $\begin{array}{l}\text { Anterior or posterior crossbite with more than } 1 \mathrm{~mm} \text { but 2-mm discrepancy between retruded contact } \\
\text { position and intercuspal position. }\end{array}$ \\
\hline & d & Displacement of teeth more than $2 \mathrm{~mm}$ but less than or equal to $4 \mathrm{~mm}$. \\
\hline & e & Lateral or anterior open bite greater than $2 \mathrm{~mm}$ but less than or equal to $4 \mathrm{~mm}$. \\
\hline & f & Increased and complete overbite without labial or palatal trauma. \\
\hline \multirow[t]{7}{*}{ Grade 2 (little) } & a & Increased overjet more than $3.5 \mathrm{~mm}$ but less than $6 \mathrm{~mm}$ with competent lips. \\
\hline & $\mathrm{b}$ & Reverse overjet more than $0 \mathrm{~mm}$ but less than or equal to $1 \mathrm{~mm}$. \\
\hline & c & $\begin{array}{l}\text { Anterior or posterior crossbite with less than or equal to a 1-mm discrepancy between retruded contact } \\
\text { position and intercuspal position. }\end{array}$ \\
\hline & d & Displacement of teeth more than $1 \mathrm{~mm}$ but less than or equal to $2 \mathrm{~mm}$. \\
\hline & e & Increased overbite more than or equal to $3.5 \mathrm{~mm}$ without gingival contact. \\
\hline & f & Prenormal or postnormal occlusions with no other anomalies. \\
\hline & g & Includes up to half a unit discrepancy. \\
\hline Grade 1 (none) & & Extremely minor malocclusions, including displacements of less than $1 \mathrm{~mm}$. \\
\hline
\end{tabular}


Supplementary Table S3. Nonresponse analysis $(n=7393)$

\begin{tabular}{|c|c|c|c|}
\hline Characteristics & Included ( $n=3048)$ & Excluded $(n=4345)$ & $\mathrm{P}$ value* \\
\hline \multicolumn{4}{|l|}{ Child } \\
\hline Age, $\mathrm{y}^{\dagger}$ & $9.74(9.53-10.03)$ & $9.75(9.55-10.18)$ & 0.077 \\
\hline Missing (\%) & $0(0.0)$ & $1531(35.2)$ & \\
\hline Gender (\%) & & & 0.599 \\
\hline Male & $1517(49.7)$ & $2189(50.4)$ & \\
\hline Female & $1531(50.2)$ & 2155 (49.6) & \\
\hline Ethnicity $(\%)^{\ddagger}$ & & & $<0.001$ \\
\hline Dutch & 2045 (67.1) & $2147(49.4)$ & \\
\hline Non-Dutch & $981(32.2)$ & $1973(45.4)$ & \\
\hline Missing & $22(0.7)$ & 225 (5.2) & \\
\hline 10TN-DHC (\%) & & & 0.136 \\
\hline No and little need & 1137 & 614 & \\
\hline Borderline need & 765 & 371 & \\
\hline Missing & $0(0.0)$ & 2708 (62.3) & \\
\hline $10 T N-A C(\%)^{\S}$ & & & 0.958 \\
\hline No and little need & $1691(55.5)$ & $908(20.9)$ & \\
\hline Borderline need & $1006(33.0)$ & $535(12.3)$ & \\
\hline Definite need & 247 (8.4) & $136(3.1)$ & \\
\hline Missing & $104(3.4)$ & 2766 (3.6) & \\
\hline COHIP-Ortho score ${ }^{*, \S}$ & $50.00(45.00-52.00)$ & $50.00(45.00-52.00)$ & 0.963 \\
\hline Missing (\%) & $0(0.0)$ & $3522(81.1)$ & \\
\hline Missing teeth $(\%)^{\S}$ & & & 0.067 \\
\hline No missing teeth & 2606 (85.5) & 1374 & \\
\hline Hypodontia & $163(5.3)$ & 83 & \\
\hline Impacted & $201(6.6)$ & 138 & \\
\hline Missing & 78 (2.6) & $2750(63.3)$ & \\
\hline Overjet $(\%)^{\S}$ & & & 0.012 \\
\hline None & $1716(56.3)$ & $971(22.3)$ & \\
\hline Missing & $48(1.6)$ & 2735 (62.9) & \\
\hline Crossbite $(\%)^{\S}$ & & & 0.742 \\
\hline None & 1995 (65.5) & $1069(24.6)$ & \\
\hline Crossbite & $827(27.1)$ & $433(10.0)$ & \\
\hline Missing & $226(7.4)$ & $2843(65.4)$ & \\
\hline Displacement $(\%)^{\S}$ & & & 0.024 \\
\hline None & $389(12.8)$ & 249 (5.7) & \\
\hline Displacement & 2549 (83.6) & $1339(30.7)$ & \\
\hline Missing & $110(3.6)$ & $2760(63.5)$ & \\
\hline Overbite $(\%)^{\S}$ & & & 0.202 \\
\hline None & 1917 (62.9) & $1016(23.4)$ & \\
\hline Open bite & $282(9.3)$ & $177(4.1)$ & \\
\hline Overbite & 692 (22.7) & $356(8.2)$ & \\
\hline Missing & $157(5.2)$ & 2796 (64.3) & \\
\hline Other $(\%)^{\S}$ & & & 0.532 \\
\hline No other traits & 1426 (46.8) & $739(17.0)$ & \\
\hline Good buccal occlusion & $1235(40.5)$ & 691 (15.9) & \\
\hline Posterior lingual crossbite & $7(0.2)$ & $3(0.1)$ & \\
\hline Submerged teeth & $0(0.0)$ & $1(0.0)$ & \\
\hline Partially erupted teeth & $131(4.3)$ & $80(1.8)$ & \\
\hline Supernumerary teeth & $12(0.4)$ & $6(0.1)$ & \\
\hline Missing & $237(7.8)$ & $2825(65.0)$ & \\
\hline
\end{tabular}




\section{Supplementary Table S3. Continued}

\begin{tabular}{|c|c|c|c|}
\hline Characteristics & Included ( $n=3048)$ & Excluded $(n=4345)$ & $\mathrm{P}$ value \\
\hline \multicolumn{4}{|l|}{ Parent } \\
\hline Maternal educational level (\%) & & & $<0.001$ \\
\hline Low & $982(32.2)$ & $1443(33.2)$ & \\
\hline High & $1865(61.1)$ & $1529(35.2)$ & \\
\hline Missing & $201(6.6)$ & $1373(31.6)$ & \\
\hline Paternal education level (\%), & & & $<0.001$ \\
\hline Low & $970(31.8)$ & $1230(28.3)$ & \\
\hline High & $1693(55.5)$ & $1431(32.9)$ & \\
\hline Missing & $385(12.6)$ & $1684(38.8)$ & \\
\hline Net household income $(\%)^{\ddagger}$ & & & $<0.001$ \\
\hline$<€ 2400$ & $618(20.3)$ & $981(22.6)$ & \\
\hline$>€ 2400$ & $2111(69.3)$ & $1790(41.2)$ & \\
\hline Missing & $319(10.5)$ & $1574(36.2)$ & \\
\hline Family composition (\%) & & & $<0.001$ \\
\hline One parent & $2540(83.3)$ & $2497(57.5)$ & \\
\hline Two parents & $300(9.8)$ & $488(11.2)$ & \\
\hline Missing & $208(6.8)$ & $1360(31.3)$ & \\
\hline \multicolumn{4}{|c|}{ 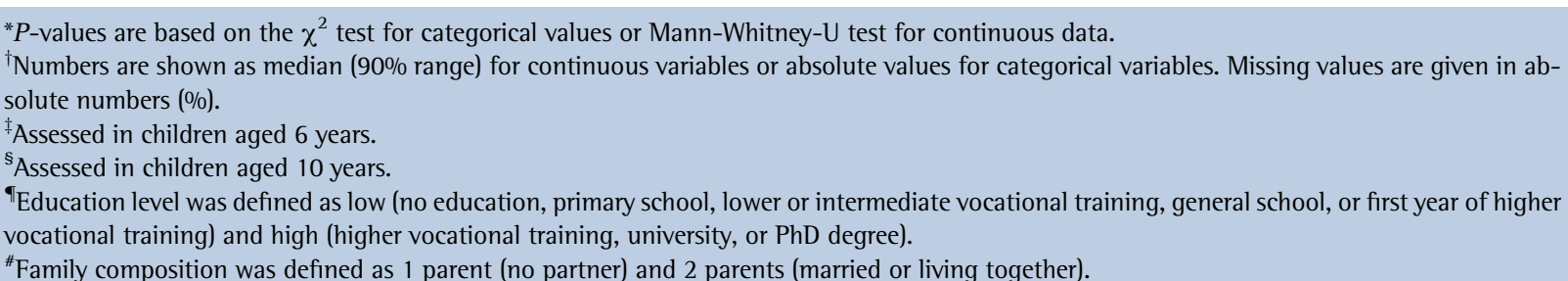 } \\
\hline
\end{tabular}

